\title{
DRIVERS OF FACULTY PEDAGOGICAL DIGITAL COMPETENCE OR HOW TO GET THINGS GOING ONLINE
}

\author{
Nora Jansone-Ratinika, Tatjana Koḳe, \\ Raimonds Strods, Māris Brants \\ Rīga Stradinš̌ University, Latvia
}

\begin{abstract}
The world's health crisis was started and the area of higher education was significantly challenged by the spread of the virus SARS-CoV-2. The academic community was forced to rethink its ways of learning and teaching dynamically. It transformed the understanding of the faculty competence as an essential component of the continuity of qualitative education, which emphasizes the need to increase the competence to work in a technology-enhanced study environment and to support students in achieving learning outcomes remotely.

The aim of the article is to explain the pedagogical digital competence of faculty, which reflects one of the research aspects covered in the State Research Programme (SRP) dedicated to mitigating the consequences of COVID-19.

The research methodology consists of a set of quantitative data, which was obtained by surveying 349 faculty from 33 higher education institutions of Latvia. In turn, a questionnaire was developed based on the obtained conclusions, performing an analysis of literature and educational guidelines. Patterns of the use of educational technologies of faculty were analyzed and described in the framework of the research. The wide analysis performed during the research can be summarized in several conclusions. (1) Skills that faculty have self-assessed as the highest primarily characterize the use of technologies and technological solutions (TTS - analogous to hardware and software) to meet students basic learning needs. In turn, skills in the use of TTS, which would help students to develop digital competence and achieve study results in line with labor market trends, are assessed lower. (2) Faculty consider themselves to be more proficient in using TTS to promote students' cognitive skills than in acquiring practical skills. (3) Faculty feel more proficient in providing feedback to students, rather than collecting it from them and performing summative rather than formative assessment. (4) The improvement of pedagogical digital competence (PDC) of faculty is driven more by cooperation with students than by administrative pressure.
\end{abstract}

Keywords: digitalization of higher education, faculty pedagogical digital competence, learning and teaching, pedagogical innovations, remote learning. 


\section{Introduction}

The spread of the SARS-CoV-2 virus to the extent of a global pandemic in 2020 has significantly shaken the international higher education area (International Association of Universities, 2020). The tension has concentrated around three trigger points, which have produced a shock-like effect in physical-epidemiological, occupational and socio-economic dimensions (Roehrig, 2020). The academic community has joined forces to ensure, in the first place, epidemiological security for all its members, to maintain and even increase professional capacity and performance, as well as community itself, has felt responsible for maintaining stability in the socio-economic dimension, and has been seriously influenced by it and overcome a number of obstacles. The focal point was the responsibility to adapt instantly to the changing situation without losing the quality of studies (Cirlan, Loukkola, 2021).

In these fluctuating circumstances, the way in which the university management and faculty actions are operated is marked by two successive approaches. Spring 2020 is characterized by the rapid reactive action required to transform the campus-based study process to remote learning. A proactive approach to the adaptation of new habits ensures the succession, when the organisers and implementers of the study process have strived to anticipate the expected limitations and facilitations, and look into the future in order to develop, as far as possible, flexible further development strategies. To ensure that the solutions are not only based on ad-hoc short-term responses but also to jointly develop a long-term vision at the state level, the State Research Programme (SRP) of Latvia "Life with COVID-19: Evaluation of overcoming the coronavirus crisis in Latvia and recommendations for social resilience in the future" (Project/agreement No. VPP-COVID-2020/1-0013) was launched, on the results of which this article is based.

To provide students an opportunity to acquire the learning outcomes defined in the study programs to the fullest extent in an alternative way, it was necessary not only to invest in e-infrastructure but also to ensure massive pedagogical growth of faculty, which is one of the research aspects of the SRP. The complexity of the situation in Latvia, as well as in many other countries, where the study process in higher education institutions is mainly implemented on-site, is determined by the fact that the transition to remote teaching and learning does not include self-evident teaching and learning strategies. Naturally, this concept is surrounded by a halo of misunderstanding and broad interpretation. Many in the field initially associate it with distance learning, which is by no means synonymous with it. By exploring, testing, adapting, fact-finding and creating new solutions, faculty strengthen their awareness of the technology-enhanced learning and teaching (L\&T) as an overarching goal of the pedagogical activity, rather than self-serving 
digitalization as a mechanically forced trend. The technology-enhanced study process (TESP) is implemented in various L\&T approaches (Web-Facilitated, Remote, Blended, Flipped, Distance, Online, Hybrid, HyFlex, etc.), using TTS to diversify and promote students' learning experience, improve digital competence, and acquire industry-specific competencies (Parchoma, 2011; Pombo \& Moreira, 2016; Hew, Cheung, 2014; Bokolo, Phon, Kamaludin, 2020). This setting of the pedagogical process naturally encourages awareness of the need to strengthen one of the main driving forces - faculty pedagogical digital competence (PDC) - the consistent application of knowledge, skills, and attitudes needed to plan the study process, develop study content and guide L\&T in different approaches and ways, also to continuously evaluate and review the technology-enhanced study environment, based on theories, research and evaluated experience, to promote students' learning experience for the acquisition of learning outcomes corresponding to the contemporary labor market (From, 2017; Guillén-Gámez et al., 2020).

\section{Methodology}

A review of the scientific literature and education development guidelines was performed to compile an evidence-based self-assessment questionnaire for faculty of higher education institutions and colleges of Latvia. Selection of scientific articles was performed in the database Web of Science using keywords: digital competence/digital skills/digital literacy and academic staff/university lecturer. The search was limited to full text articles in English published between 2019 and 2020. Criteria for inclusion of the article: the abstract of the article reveals aspects directly/related to the digital competence of the faculty, including the integration of technologies in the study process. Of the 144 identified articles, only 13 were accepted for in-depth research and used to develop the content of the questionnaire. In the next research phase 17 national and international education development guidelines were analysed. The aim was to identify a narrative that reflects the political discourse in the field of education on the TESP and the digital competence of faculty and the results were incorporated into the content of the questionnaire.The results of the scientific literature and education development guideline analysis are not reflected in this article but can be found in the SRP final report (Jansone-Ratinika, Strods, Brants, et al., 2020). The questionnaire was developed using Google Forms and the link was sent to the e-mails of faculties, maintaining the possibility to provide an anonymous answer. Faculty e-mails were obtained by searching them on higher education institutions (HEI) websites. Survey was conducted from 13 October to 1 November 2020, during which 349 valid, fully completed questionnaires were obtained (representing $33 \mathrm{HEI}$ ). 
It was technically impossible to provide a representative sample of the faculty of Latvia because:

- the project external timeline is very short for an extensive questionnaire at a time when faculty are still trying to provide a qualitative remote learning process;

- of a lack of comprehensive statistical data on the socio-demographic parameters of the faculty of Latvia.

Thus, the survey represents those 349 faculty who have completed the questionnaire. MS Excel and SPSS programs were used for data processing, providing tabulation of results, calculation of statistical differences, and preparation of graphs.

Descriptive statistics were mainly used to reflect the results:

- frequencies of variables;

- arithmetic means for variables that provide self-assessment of skills on a scale of 1 to 5 .

In addition, the Spearman rank correlation coefficient was used to determine the interrelationships of the variables, the possible values of which range from +1 to -1 .

\section{Results}

This section reflects the results obtained in the study, which explain the self-assessment of faculty skills to use TTS in the study process, as well as the correlation of skills with the conditions determining the choice of TTS, the use of digital learning tools, and individual factors influencing faculty PDC.

To establish the faculty use of TTS in the study process (see Table 1) and to explain their PDC, the respondents were asked to evaluate 21 statements on a scale from 1 (very low-skilled) to 5 (very high-skilled). The statements are designed to cover all areas of the faculty pedagogical activity in the provision of remote learning: planning and organization of the study process; study content development; L\&T; evaluation of students' performance and study process. The average score of all considered statements (mean 3.7) demonstrates the faculty belief in using TTS not only to ensure remote learning, but also to promote interactive, personalized and engaging learning. Although the faculty self-assessment indicates that PDC is at a sufficiently high level, there are still trends that indicate that this area of the faculty competence needs to be improved. Faculty reveal that they feel more skilled to organize communication with students in the study process (mean 4.20); to create visualizations of the study content (mean 3.99) and to organize the L\&T process (mean 3.97) rather than to provide students with the opportunity to experiment (mean 3.19); to personalize the way 
students learn (mean 3.45) and to promote the acquisition of students' selfpaced learning skills (mean 3.53).

Table 1. Self-assessment of skills to use TTS (scale from 1 to 5)

\begin{tabular}{|l|l|}
\hline Statements & Mean \\
\hline To provide students with the opportunity to experiment & 3.19 \\
\hline To personalize the way students learn & 3.45 \\
\hline To promote the acquisition of students' self-paced learning skills & 3.53 \\
\hline To promote the acquisition of students' lifelong learning skills & 3.53 \\
\hline To promote students' cooperation in learning & 3.55 \\
\hline To make the form of the study organization more interactive & 3.56 \\
\hline To implement formative assessment (descriptive) & 3.58 \\
\hline To combine TTS according to different needs of the study process & 3.63 \\
\hline To promote active student learning & 3.64 \\
\hline To implement summative assessment (grading) & 3.68 \\
\hline To promote the acquisition of students' professional core skills & 3.70 \\
\hline To make the study content more interactive & 3.72 \\
\hline To receive feedback from students & 3.74 \\
\hline To diversify learning and teaching methods & 3.77 \\
\hline To develop students' cognitive skills (thinking, reasoning) & 3.78 \\
\hline To structure study content in Learning Management System (Moodle) & 3.84 \\
\hline To provide feedback to students & 3.89 \\
\hline To promote the acquisition of students' theoretical knowledge & 3.91 \\
\hline To organize the learning and teaching process & 3.97 \\
\hline To create visualizations of the study content & 3.99 \\
\hline To organize communication with students in the study process & 4.20 \\
\hline
\end{tabular}

The results demonstrate the higher self-confidence of the faculty in organizing the study process and ensuring the support using TTS rather than implementing the learning characterized by the up to date tendencies of higher education that involves the activization of student learning in different ways. Also faculty feel more skilled to promote the acquisition of students' theoretical knowledge (mean 3.91) than to promote the acquisition of students' professional core skills (mean 3.70) or to promote students' cooperation in learning (mean 3.55). It can be concluded that faculty feel more skilled in promoting students' cognitive abilities than in developing practical skills and promoting cooperation to solve higher-level tasks. 
More faculty-focused tendencies are also observed in the assessment process, as that higher self-assessment rates are discovered of skills to provide feedback to students (mean 3.89) and to implement summative assessment (mean 3.68) rather than to alternative activities in which students are more meaningfully involved: to receive feedback from students (mean 3.74) and to implement formative assessment (mean 3.58). The results suggest that faculty technology use habits should be developed to support learning goals and needs more proficiently, while PDC should be guided and adapted to strengthening and revitalizing the student-centered approach within the form of remote learning.

The use of selected TTS in the study process plays a significant role in providing a technology-enhanced environment. In turn, the choice of TTS can be determined by various factors. Primarily, of course, it is the availability of TTS, but the rapid development of digitalization of education in recent years has created a natural demand for university administration to provide faculty with wide access to various TTS, and therefore the choice is already determined by various factors shown in Table 2 . In general, it can be concluded that based on the choice of TTS there is no convincing correlation with the self-assessment of faculty skills, or a small correlation is observed only in a few cases, which suggests that developed technological environment provides opportunities for pedagogical digital skills development, but is not an influential factor for a high level of pedagogical digital skills.

The results show that if the faculty involve students in the choice of TTR integration and jointly create new solutions, then faculty also feel more skilled in promoting students' cognitive processes $(r s=.365)$, opportunity to experiment ( $r s=.364$ ), and active learning process ( $r s=.362$ ). There is a smaller but also significant correlation between making a common choice of TTS integration or creating new solutions with the ability to evaluate the study process and self-assessment of feedback organization. Respectively, if the TTS to be integrated in the study process are coordinated with the students, or new solutions are created together, then the faculty also feel more skilled in receiving ( $r s=.338)$ or providing ( $r s=.298)$ feedback, as well as implement summative ( $r s=.279)$ or formative $(r s=.256)$ assessment in the evaluation of students' performance. When evaluating correlations, the conclusion can be put forward that the involvement of students in deciding on the TTS to be used and creating new TTS solutions together can contribute to the provision of a meaningful and comprehensive study process in a technology-enhanced study environment. By other means, considering the issue of TTS choice in another cross-section, there is no positive or negative correlation between the requirements of the university administration to integrate certain TTS in the study process and the self-assessment of faculty skills to use the TTS in the study process. 
Table 2. Correlation between the choice of TTS and the skills of faculty

\begin{tabular}{|c|c|c|c|c|c|}
\hline \multirow[b]{2}{*}{$\begin{array}{l}\text { Skills to use TTS in the study } \\
\text { process: }\end{array}$} & \multicolumn{5}{|c|}{$\begin{array}{l}\text { The implementation of TTS } \\
\text { in the study process is determined by }\end{array}$} \\
\hline & 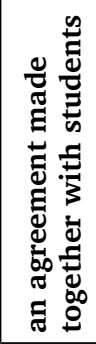 & 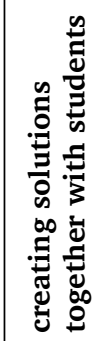 & 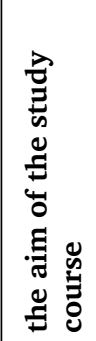 & 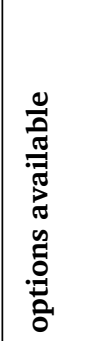 & 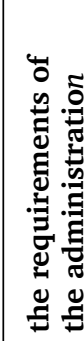 \\
\hline $\begin{array}{l}\text { To implement summative } \\
\text { assessment (grading) }\end{array}$ & 0.239 & 0.279 & 0.142 & 0.180 & 0.042 \\
\hline $\begin{array}{l}\text { To implement formative } \\
\text { assessment (descriptive) }\end{array}$ & 0.247 & 0.256 & 0.177 & 0.172 & 0.013 \\
\hline $\begin{array}{l}\text { To promote active student } \\
\text { learning }\end{array}$ & 0.297 & 0.362 & 0.228 & 0.242 & 0.109 \\
\hline $\begin{array}{l}\text { To promote students' cooperation } \\
\text { in learning }\end{array}$ & 0.245 & 0.338 & 0.199 & 0.184 & 0.141 \\
\hline $\begin{array}{l}\text { To provide students' with the } \\
\text { opportunity to experiment }\end{array}$ & 0.270 & 0.364 & 0.118 & 0.155 & 0.064 \\
\hline To receive feedback from students & 0.274 & 0.338 & 0.243 & 0.242 & 0.013 \\
\hline To provide feedback to students & 0.240 & 0.298 & 0.271 & 0.257 & 0.034 \\
\hline $\begin{array}{l}\text { To make the study content more } \\
\text { interactive }\end{array}$ & 0.178 & 0.251 & 0.149 & 0.200 & 0.016 \\
\hline $\begin{array}{l}\text { To develop students' cognitive } \\
\text { skills (thinking, reasoning) }\end{array}$ & 0.275 & 0.365 & 0.213 & 0.241 & 0.023 \\
\hline $\begin{array}{l}\text { To promote the acquisition of } \\
\text { students' professional core skills }\end{array}$ & 0.221 & 0.291 & 0.224 & 0.249 & 0.063 \\
\hline $\begin{array}{l}\text { To promote the acquisition of } \\
\text { students' self-paced learning skills }\end{array}$ & 0.264 & 0.317 & 0.195 & 0.188 & 0.041 \\
\hline
\end{tabular}

Note: The green color shows a strong correlation, while red shows a weak one

The authors of the study, based on the obtained results, put forward the thesis that university faculty accept and fulfill the requirements of the administration, but they do not clearly direct the development of skills to use certain TTS in the study process. Although there is no close correlation between the choice of TTS, which is determined by the aim of the study course and the self-assessment of faculty skills to use TTS, the authors of the study believe that this would be one of the areas of faculty skills development so that students gain a solid experience of using TTS for learning 
purposes. Hypothetically, it could also contribute to the development of students' self-paced learning skills, as TTS would serve as a meaningful and independently used support tool. Analyzing the overall results, the thesis emerges that the self-assessment of faculty skills to use TTS in the study process is more closely correlated with the involvement of students, rather than the commitment or demand of the environment, university administration or educational goals.

Table 3. Correlation between the choice of digital learning resources and the skills of faculty

\begin{tabular}{|c|c|c|c|}
\hline \multirow[b]{3}{*}{$\begin{array}{l}\text { Skills to use TTS in the } \\
\text { study process: }\end{array}$} & \multicolumn{3}{|c|}{ Often used in the study process: } \\
\hline & $22 \%$ & $26 \%$ & $69 \%$ \\
\hline & $\begin{array}{l}\text { digital learning } \\
\text { resources } \\
\text { created by } \\
\text { other authors }\end{array}$ & $\begin{array}{l}\text { self-adapted } \\
\text { digital learning } \\
\text { resources created } \\
\text { by other authors }\end{array}$ & $\begin{array}{l}\text { self-created } \\
\text { digital } \\
\text { learning } \\
\text { resources }\end{array}$ \\
\hline To diversify L\&T methods & 0.100 & 0.178 & 0.257 \\
\hline $\begin{array}{l}\text { To promote active student } \\
\text { learning }\end{array}$ & 0.170 & 0.211 & 0.254 \\
\hline $\begin{array}{l}\text { To promote students' } \\
\text { cooperation in learning }\end{array}$ & 0.115 & 0.142 & 0.263 \\
\hline $\begin{array}{l}\text { To personalize the way } \\
\text { students learn }\end{array}$ & 0.160 & 0.179 & 0.241 \\
\hline $\begin{array}{l}\text { To develop students' } \\
\text { cognitive skills (thinking, } \\
\text { reasoning) }\end{array}$ & 0.098 & 0.133 & 0.245 \\
\hline $\begin{array}{l}\text { To promote the acquisition } \\
\text { of students' professional } \\
\text { core skills }\end{array}$ & 0.086 & 0.087 & 0.245 \\
\hline
\end{tabular}

Integrating digital learning resources into the study process is an important activity in creating a technology-enhanced study environment. Research statistics show that faculty more often develop (69\%) digital learning resources themselves than adapt (26\%) or use existing (22\%) resources. The results could indicate both the high level of digital skills of faculty in developing learning resources as well as L\&T needs that require individualized solutions, in addition to the fact that faculty may not have access to databases to search for such resources. The third table shows how the contribution of faculty to the development of digital learning resources and their use correlates with the self-assessment of faculty skills. In the overview, there is a tendency, as faculty invest more in the adaptation or development of learning resources, the closer the correlation with the 
higher self-esteem of skills. On one hand, the trend is very logical and can be seen as an axiom of learning, while on the other hand, the benefits are worth investing time and intellectual resources. There is a correlation between the faculty ability to create their own digital learning resources and the provision of active ( $r s=.254)$, student-involved ( $r s=.263$ ) learning process, as well as diversification of L\&T methods ( $r s=.257$ ). The observed correlations develop the student-centeredness of the technology-enhanced study process and therefore can also be considered as meaningful drivers of the faculty PDC.

Table 4. Correlation between factors influencing the skills of faculty

\begin{tabular}{|c|c|c|c|c|c|c|}
\hline $\begin{array}{l}\text { Skills to use TTS in the } \\
\text { study process: }\end{array}$ & 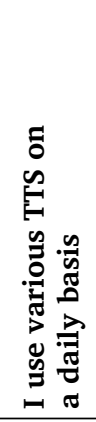 & 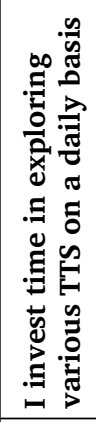 & 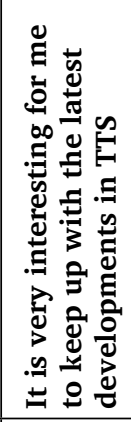 & 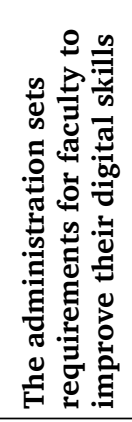 & 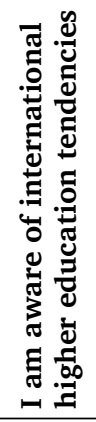 & 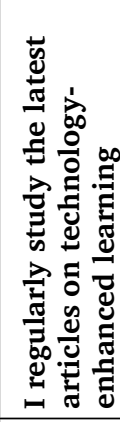 \\
\hline To diversify L\&T methods & 0.256 & 0.350 & 0.368 & 0.099 & 0.229 & 0.263 \\
\hline $\begin{array}{l}\text { To promote active student } \\
\text { learning }\end{array}$ & 0.313 & 0.372 & 0.424 & 0.167 & 0.247 & 0.339 \\
\hline $\begin{array}{l}\text { To promote students' } \\
\text { cooperation in learning }\end{array}$ & 0.262 & 0.376 & 0.364 & 0.168 & 0.227 & 0.338 \\
\hline $\begin{array}{l}\text { To personalize the way } \\
\text { students learn }\end{array}$ & 0.240 & 0.311 & 0.397 & 0.117 & 0.232 & 0.335 \\
\hline $\begin{array}{l}\text { To provide students with the } \\
\text { opportunity to experiment }\end{array}$ & 0.226 & 0.339 & 0.409 & 0.091 & 0.218 & 0.393 \\
\hline $\begin{array}{l}\text { To receive feedback from } \\
\text { students }\end{array}$ & 0.265 & 0.289 & 0.389 & 0.082 & 0.226 & 0.293 \\
\hline $\begin{array}{l}\text { To develop students' } \\
\text { cognitive skills (thinking, } \\
\text { reasoning) }\end{array}$ & 0.252 & 0.346 & 0.377 & 0.032 & 0.251 & 0.228 \\
\hline $\begin{array}{l}\text { To promote the acquisition } \\
\text { of students' professional core } \\
\text { skills }\end{array}$ & 0.219 & 0.309 & 0.345 & 0.042 & 0.229 & 0.211 \\
\hline $\begin{array}{l}\text { To promote the acquisition } \\
\text { of students' lifelong learning } \\
\text { skills }\end{array}$ & 0.239 & 0.323 & 0.377 & 0.137 & 0.272 & 0.363 \\
\hline $\begin{array}{l}\text { To promote the acquisition of } \\
\text { students' self-paced learning } \\
\text { skills }\end{array}$ & 0.223 & 0.259 & 0.300 & 0.069 & 0.261 & 0.270 \\
\hline
\end{tabular}


Faculty are the key drivers of innovation in higher education, so it is important to understand the impact of the factors summarized in Table 4 on the development of their PDC. Generalizing the obtained results, it is possible to draw inference that the faculty personal motivation to improve their competence to develop a TESP is closely related to high self-assessment of pedagogical digital skills. Table 4 includes such TTS use skills that characterize a distinctly student-centered approach and contribute to a meaningful student learning experience. Although the factors influencing skills are not strictly separable, it can be observed that the internal motivation of lecturers, or interest in following TTS development, correlates more strongly with high skills self-assessment to use TTS in the study process than daily TTS use, investing time in TTS research, following higher education development trends or even analysis of scientific articles. Similar to Table 1 , in this situation there is neither a strongly positive nor a negative correlation between the requirements of the university administration to improve skills and the self-assessment of faculty skills to use TTS in the study process. Accordingly, it can be assumed that the definition of strict administrative requirements for skills development could be replaced by a greater emphasis on creating a supportive and mutual learning environment. The authors of the study believe that the development of faculty PDC is mainly purposefully and comprehensively driven by a set of all positive correlation factors, and not by a single factor.

\section{Discussion}

Analyzing the obtained results, which reflect the faculty self-assessment of skills to use TTS in the study process, two levels can be distinguished: basic and mastery, which are complementary and more broadly characterize the faculty PDC explained in the introduction. The basic level includes basic necessities for ensuring a technology-enhanced, remote learning process in the current situation. To provide remote learning, faculty must have access to synchronous and asynchronous L\&T technical solutions, as well as an online learning environment that ensures the integration of these solutions and the availability of digital learning materials to students. However, at the basic level of pedagogical categories, the faculty is able to communicate effectively and promptly with students in order to ensure accessible learning opportunities for all, digital learning resources created by other authors are used most common or they are minimally adapted to the specifics of the study course and the learning needs of students. The TTS study process is mostly used to visualize the content of the studies, demonstrate learning resources, and visually supplement faculty explanations. L\&T are mostly focused on promoting the theoretical knowledge and cognitive 
capacity of students. The assessment of student performance and results achieved is mainly based on summative assessment and feedback providing rather than collecting strategies. At the mastery level, the use of TTS is transformed from the provision of the teaching and visualization of information to the development of a full-fledged and active learning process for students, already including complex TTS in the study process. In addition, different TTS are used to develop different L\&T methods. The process of learning the content of studies focuses on strengthening professional skills, promoting cooperation and mutual learning, as well as experimenting to create new solutions. Digital learning resources are created unassistedly and personalized according to various needs of students in order to promote the development of students' self-paced learning skills. The students' performance in the process is assessed using a formative technique so that the study results can be measured more objectively and faculty pay great attention to receiving feedback from students with the aim to be able to improve the study process.

Regardless of the level of PDC of faculty, it is always possible to improve it and more fully orient faculty activities to the provision of a student-centered L\&T approach in a remote format. Analyzing the research results, several driving forces of pedagogical digital competence of faculty have been put forward and interpreted:

Involvement of students in designing and managing of the study process. The results of the research demonstrate that higher self-assessment of PDC is provided by faculty who not only involve students in the choice of TTS in the study process, but also work together to develop new solutions and generally delegate more responsibility for the learning process and outcomes to students themselves. The more students are involved in decision-making, the wider technological opportunities are discovered in the study process, which also improves faculty skills and expands their view on technology in general.

Efforts in the development of personalized learning resources. The development of learning resources corresponding to the needs of students and the goals of the study course will promote not only the improvement of the faculty PDC, but also the promotion of student-centered learning. The development of meaningful digital learning resources is labour\&time-intensive but will make a significant contribution to promoting both synchronous and asynchronous, as well as self-paced learning. The development of learning resources will naturally contribute to the improvement of faculty PDC, as it will be necessary to think of new ways of finding innovative TTS and pedagogical solutions and adapting them to L\&T contexts.

Combining content sources and forms for growth. The more skilled faculty will be in finding the various sources for the growth of PDC, the 
more it will result in higher pedagogical performance with students - both in the face-to-face and online formats. Greater emphasis should be placed not only on the day-to-day use of TTS but also on experimenting with the latest digital solutions offered in the industry and beyond. The results of the research demonstrate that the faculty internal motivation and interest in following innovations prevails over other influences of the PDC, which repeatedly reminds of the role of the faculty professional vocation, which must be appreciated and supported.

There are certain limitations of this study and factors should be taken into account when continuing research in this area: the sampling limit does not allow to fully study the situation in the population; the circumstances of the emergency situation dictate a number of constraints that affect both the acquisition and the interpretation of the data; long-term and comparative research is needed to reveal the pedagogical efficiency of the use of TTR; measurements of the pedagogical efficiency of continuing education for academic staff is a separate area of research, which requires systemic methodological renewal and determined input.

\section{Conclusions}

The development of a supportive and mutual learning-oriented professional mastery development plaform plays an important role when it is necessary not only to transform the L\&T in the higher education area from on-campus to remote but also to continuously improve the quality of the study process. The authors of the study make recommendations for the improvement of faculty PDC at two levels:

\section{Individual:}

- to master the simple use of TTR in the study process and move towards more complex TTR acquisition to create a more interactive, engaging, and skills-oriented L\&T;

- to align the choice of using TTS in the study process with the learning goals and to make the final decision in the discussion with the students, so that the learning process corresponds to their needs;

- to ground the improvement of the PDC in the results of the evaluation of the study process, which have been obtained by analyzing the collected analytics on the effectiveness of L\&T in the TESP.

\section{Institutional:}

- to promote the development of a culture of collegial mutual hospitation of faculty classes with an intention to approbate and evaluate the efficiency of the use of TTS in the study process;

- to promote the development of a culture of co-development and sharing of digital learning resources through co-operation and mutual 
support, at the same time, through proper respect for copyright and principles of academic integrity;

- to mitigate faculty workload in terms of performing administrative tasks to encourage and release greater resources for the growth of pedagogical mastery, which is considered to be the core competence in the designing of a highly efficient technology-enhanced study process.

\section{References}

Bokolo Jr. A., Phon, D., \& Kamaludin, A. B. (2020). Blended Learning Adoption and Implementation in Higher Education: A Theoretical and Systematic Review. Technology, Knowledge and Learning. https://doi.org/10.1007/s10758-020-09477-z

Cirlan, E., Loukkola, T. (2021). Internal quality assurance in times of COVID-19. https:// eua.eu/downloads/publications/internal\%20qa.pdf

From, J. (2017). Pedagogical Digital Competence - Between Values, Knowledge and Skills. Higher Education Studies, 7(2), 43-50. doi: 10.5539/hes.v7n2p43

Guillén-Gámez, F. D., Mayorga-Fernández, M. J., Bravo-Agapito, J. et al. (2020). Analysis of Teachers' Pedagogical Digital Competence: Identification of Factors Predicting Their Acquisition. Technology, Knowledge and Learning. doi: 10.1007/s10758-019-09432-7

Hew, K. F., Cheung, W. S. (2014). Using Blended Learning: Evidence-Based Practices. Singapore: Springer. ISBN 978-981-287-089-6

International Association of Universities. (2020, August). Regional/National Perspectives on the Impact of COVID-19 on Higher Education. https://www.iau-aiu.net/IMG/pdf/iau_ COVID-19_regional_perspectives_on_the_impact_of_COVID-19_on_he_july_2020_pdf

Jansone-Ratinika, N., Strods, R., Brants, M., Koke, T., Grigoroviča, E., Blese, I., Smirnova, D., Sabel,nikovs, O. (2020). Pedagogical digital competences of the academic staff self-assessment and improvement offer. https://www.rsu.lv/projekts/dzive-ar-COVID-19

Parchoma, G. (2011). Toward Diversity in Researching Teaching and Technology Philosophies-in-Practice in e-Learning Communities. In Handbook of Research on Methods and Techniques for Studying Virtual Communities: Paradigms and Phenomena (pp. 61-86). Pennsylvania: IGI Global. doi: 10.4018/978-1-60960-040-2.ch004

Pombo, L., Moreira, A. (2016). Tips Towards Tackling Distance Education Modules: The Case of the Doctoral Program on Multimedia in Education. In A. Moreira (Ed.), Handbook of Research on Engaging Digital Natives in Higher Education Settings (pp. 328342). Pennsylvania: IGI Global. doi: 10.4018/978-1-5225-0039-1.ch015

Roehrig, P. (2020). From Chaos to Catalyst. Surf the pandemic shockwaves to keep your business relevant. Cognizant Digital Business (April). Cognizant. https://www.cognizant. com/whitepapers/from-chaos-to-catalyst-codex5607.pdf 